\title{
WATER RELATIONSHIPS OF PLANTS IN ARID AND SEMI-ARID CONDITIONS
}

$T^{3}$ HE part played by Unesco in stimulating interest in the problems of the drier regions of the surface of the Earth is widely recognized. Its excellent series of symposia, covering hydrology, utilization of saline water, plant ecology, human and animal ecology, wind and solar energy, and micrometeorology, has done much to crystallize our current concepts of water as an ecological factor and particularly to emphasize the physical background in which it operates. These discussions were extended to the level of the individual plant at a symposium organized in Madrid during September 1959.

Considered as a whole, the two published volumes of the Canberra symposium on micrometeorology and the two volumes of the Madrid symposium, which have yet to appear, provide not only one of the best modern treatments of plant-water relations but also illustrate clearly the way in which plant ecology is casting its traditional shackles and emerging as an active experimental discipline. The Madrid symposium, although leavened with a few soil physicists and plant physiologists, was numerically dominated by plant ecologists. Among these were included representatives of the three modern categories: (i) the 'chroniclers', whose penchant for description and cartography readily translates suggestions into irrefutable dogma and leads to the creation of beautiful but often meaningless mapsmultivariate analysis apparently does not yet qualify for an expense account ; (ii) the 'partialists', whose methods have not advanced beyond the era of Livingston and Maximov, and whose thought is restricted to the confines of the plant; and (iii) the 'totalists', whose concern is with the entire soil-plantatmosphere system. It is no accident that the modern approach to experimental ecology represented by the third category should have developed within the applied science of agriculture but simply reflects the stimulus arising from close association between people investigating detailed aspects of different parts of the same system. One of the finest examples of an ecological investigation is that reported at Madrid by $\mathbf{R}$. O. Slatyer on the water relations of two natural communities in Australia. Here, soil physicists, plant physiologists and micrometeorologists are working together and each has a full appreciation of the complete system.

It is also no accident that this approach should emerge first with the study of water because the responses of the plant to water are less complex than to other ecological factors such as light or temperature. Knowledge of the control of the water supply has now advanced to the stage of complete quantitative description, although the values of some parameters are far from exact. Those which are least perfectly known include moisture-release curves, surface roughness, stomatal conductance and the variations in extent of the root-zone with time, species and environment. Several contributors discussed these. The location and sizes of the resistances in the plant to liquid flow are uncertain, although it is now clear that plants may experience an adverse deficit of water in the leaves with the soil water at 'field capacity' when the potential transpiration exceeds $\sim 4-5 \mathrm{~mm}$./day. In order to evaluate this and other problems intelligently and to remove general confusion, the status of water in all parts of the soilplant-atmosphere system must be expressed in equivalent terms. The logical terminology is that of thermodynamics, and all members of the conference unanimously agreed to use energy terms and units henceforth. The water potential (difference in free energy between the water contained in the soil or plant system and pure free water at atmospheric pressure) should be used for the quantity normally associated with total soil-moisture stress and diffusion pressure deficit or suction pressure. It is determined by three components: (1) the osmotic potential, which takes account of all dissolved materials in the soil solution or plant sap and is usually called the osmotic pressure ; (2) the pressure potential, which is associated with the total pressure difference in the system, that is to say, with the difference in pressure between the water in a tensiometer and that in the adjacent soil or with the turgor pressure of plant cells; and (3) the matric potential, which depends on the solid matrix and the forces of retention of water in the matrix and which has been associated with terms previously called soil suction or moisture tension but which is usually ignored in plant systems.

Knowledge of the response of plants to water supply is in a less happy position than is our appreciation of transpiration. The differing responses between species, and within the one species with phase of growth, to the apparent soil-water deficit arise mainly from differences in the rate of extension of the root system, from measuring the deficit at one or two depths only, and from the difficulties associated with obtaining an integrated value of the water deficit in the soil actually occupied by roots. With increasing values of the water deficit in soil fully permeated by roots at any point of time, growth appears to decrease over the range of water potential from $\sim-0.01$ ('field capacity') to $\sim-1.5$ joules/gm. ('wilting point'), but the form of the relationship is modified by the level of potential transpiration and other environmental aspects. R. M. Hagan, N. S. Petinov and S. A. Taylor discussed irrigation within this context.

Survival under dry conditions-the problem of drought resistance--is still little understood. The mechanisms involved, discussed by H. R. Oppenheimer, A. M. Migahid and other contributors, are complex and numerous. Some of these, such as extensive root systems, leaf fall and stomatal closure associated with low cuticular conductance, prolong the period during which the water supply of tissue capable of growth can be maintained. The reaction of cells and tissues to drying, analysed by O. Stocker, also differ, and the behaviour of the whole plant is related to the resultant of the complex interactions which occur between varying proportions of cells of differing responses. One of the most exciting developments in this field is the hardening of plants prior to sowing which has been developed by Soviet scientists. 
Increases in yield from 10 to 40 per cent are claimed. These and other contributions from the U.S.S.R. to the understanding of the reactions of plants to water and to heat were discussed by N. S. Petinov and P. A. Genkel.

The discussions will be published in two parts: (1) Reviews of research prepared as background material on "The Income and Loss of Water" (F. L. Milthorpe), "Soil Water Relations" (W. R. Gardner), "Physiological and Morphological Changes in Plants due to Water Deficioncy" (O. Stocker), "Adaptation to Drought-Xerophytism" (H. R. Oppenheimer), "Methods of Research on Water Relations" (F.
Eckardt), "The Management of Native Vegetation" (R. M. Moore), "Principles of Dry Land Crop Management" (S. A. Taylor), "Significance of Fallow as a Management Technique" (W. J. Staple), "Principles of Irrigated Cropping" (R. M. Hagan and Y. Vaadia), "Survey of Research on the Water Regimes of Plants" (P. A. Genkel and K. A. Bodanova), "The Water Regime of Plants on Saline Soils" (B. P. Strogonov); (2) Proceedings of the symposium, which include about forty papers contributed on detailed aspects within the above fields by workers from sevanteen different countries.

\section{F. L. MiLthorpe}

\section{MINING GEOPHYSICS}

$\mathrm{T}$ THE second Nordic Meeting for Mining Geophysics was held at Haandværkerforeningen, Copenhagen, during December 7-8. More than fifty geophysicists and technicians, including five from Finland, oleven from Norway, and eighteen from Sweden, attended. The sessions were presided over by Haakon Brækken from Trondheim, Norway, chairman of the planning committee.

The technical programme included twelve papers, two of which were concerned with Greenland. B. Sjögren (Sweden) reported on a seismic refraction and reflexion investigation on the Malmberget glaciers. The area surveyed lies about $20 \mathrm{~km}$. south-east of Mestersvig, Kong Oscars Fjord, east Greenland, and the purpose of the survey was to determine the thickness of the ice-moraine layer of the glaciers. The bed-rock is mainly sandstone from the Carboniferous period which is superseded by tertiary granite. The bed-rock velocities measured varied from 4,800 to $5,400 \mathrm{~m}$. per sec. while the longitudinal wave velocity in the ice-moraine layer was between 3,700 and $3,800 \mathrm{~m}$. $/ \mathrm{sec}$.; the transverse wave velocity in this layer was of the order of 1,600$1,700 \mathrm{~m}$./sec. The measured thickness of the icemoraine cover varied from 120 to $450 \mathrm{~m}$. The bedrock under the glaciers was discovered to be U-dale shaped with relatively shallow slopes while the rock walls on the sides of the glaciers climbed very steeply to about $700 \mathrm{~m}$. above the glacier surface. The second paper dealing with Greenland, "A Study of the Disturbances due to Salt-water on Minor Loopframe Indications", was presented by J. Bondam (Denmark). The survey is part of experimental measurements carried out near Narssaq, south-wost Greenland.

The important problem of the elucidation of structure was illustrated by G. F. Sakshaug (Norway). Electromagnetic, magnetic, and self-potential surveys have been employed in the exploration of copper mineralization at Bidjovagge, Finmark (Northern Norway). Electromagnetic surveys have been conducted as a general reconnaissance method as well as towards the examination of detail. Electromagnetic anorralies are largely confined to beds of graphito shalo occurring in the area. Magnetic surveys define magnetite-bearing greenstones. Selfpotential surveys give essentially a map of the graphite shale under the moraine cover. All three methods have been essential to the interpretation of the structural relations in the area. Irrogularities in the anomalics reflect tectonic disturbances, and ore-mineralizations-as diamond drilling has con- firmed-are related to areas of intense disturbance. Another example of structure mapping was given by $V$. Münther (Denmark) in a presentation of a magnetic survey of Bornholm and its application to the geology, especially the tectonics. The island has been covered by magnetic stations in squares, the side-length being 500 metres. Moreover, a considerable number of traverses has been established, stations distances being from 10 to $20 \mathrm{~m}$. apart. It has in this way been possible to correct the previous boundary lines between granite and sandstone. Known faults have been traced in more detail and older faults have been shown. In the granitic area the magnetic contours indicate the granite variety. Interpretation of the anomaly map indicated partly stronger magnetic layers at a greater depth, partly a change in the magnetic field with time. The practical aspect of the survey is the economic interest in sandstone.

A case-history was demonstrated by J. Esporsen (Sweden). Magnetic and gravimetric measurements have pointed out the existence of two important and several minor ore bodies at Svappavaary near Kiruna, north Sweden. The applicability of mag. netometers and gravimeters in ore prospecting is underlined by the confirming drilling results. $J$. Nuutilainen (Finland) described gravimetric application in ore prospecting. Levelling is carried out by means of a mercury pressure-gauge and a water tube which at the same time is the measuring tape. $H$. Paarma (Finland) considered magnetic gradient measurements with regard to ore bodies and structures. A report of interest concerning the conductivity of magnetite, sulphide, and different rocks sampled in Swedish mines was given by Sture Werner (Sweden). Measurements were undertaken in fifteen sulphide-mines and twenty iron-mines. The resistivity, which is the reciprocal of the conductivity, was found to amount to $300,000-3,000,000$ ohm$\mathrm{cm}$. for the circumjacent rocks, while the value for magnetite and sulphide was usually found to be of the order $0.01 \mathrm{ohm}-\mathrm{cm}$. The resistivity increases rapidly as the percentage of magnetite decreases; for example, an ore sample with 50 per cent iron has a resistivity of about 10,000 ohm-cm. For the sulphide samples the resistivity increases slowly as the percentage of sulphide decreases. Only at a very low sulphide content do the resistivity values rise.

A new instrument for measuring the curvature in boro-holes was presented by A. Holm (Sweden), and A. Breen (Norway) discussed the employment of phase-sensitive voltmetors in mcasuring electromagnetic fields. A point of practical importance was 